\title{
Biomarkers for Evaluation of Clinical Outcomes of Hemodiafiltration
}

\author{
Kenji Sakurai \\ Hashimoto Clinic, Kanagawa, Japan
}

\section{Key Words \\ $\beta_{2}$-Microglobulin · $a_{1}$-Microglobulin · Hemodiafiltration · Uremic toxins - Removal rate - Restless legs syndrome}

\begin{abstract}
$\beta_{2}$-Microglobulin ( $\beta_{2}-M G$ ) is the substance that causes dialysis amyloidosis, and its predialysis value is useful for evaluating the quality of dialysis therapy itself. In addition, $\beta_{2}-M G$ is also an important biomarker for evaluating the removal performance of hemodialysis and hemodiafiltration (HDF). However, since $\beta_{2}-\mathrm{MG}$ has a molecular weight of $11.8 \mathrm{kDa}$ and can be efficiently removed by diffusion with existing high-performance dialyzers, a higher molecular weight substance should be used for evaluating removal performance of HDF, in which diffusion and convection are performed simultaneously. $a_{1}$-Microglobulin $\left(a_{1}-M G\right)$ has a molecular weight of $33 \mathrm{kDa}$, and it is removed by convection during dialysis. When we used $a_{1}-M G$ to evaluate the removal performance of HDF in a study based on our own cases, we were able to describe the distinctive features and benefits of HDF with precision. $a_{1}-M G$ removal rate exactly paralleled the changes in symptoms. $\mathrm{Kt} / \mathrm{V}$ and the $\beta_{2}-\mathrm{MG}$ removal rate, however, did not undergo significant changes as the symptoms fluctuated. $a_{1}-M G$ should be used as a biomarker for evaluation of clinical outcomes of HDF.
\end{abstract}

Copyright $\odot 2013$ S. Karger AG, Basel

\begin{tabular}{ll}
\hline KARGER & $\begin{array}{c}\text { ( ) 2013 S. Karger AG, Basel } \\
0253-5068 / 13 / 0351-0064 \$ 38.00 / 0\end{array}$ \\
E-Mail karger@karger.com & This is an Open Access article licensed under the terms of \\
www.karger.com/bpu & $\begin{array}{l}\text { the Creative Commons Attribution- NonCommercial-No- } \\
\text { Derivs 3.0 License (www.karger.com/OA-license), applica- } \\
\text { ble to the online version of the article only. Distribution for } \\
\text { non-commercial purposes only. }\end{array}$
\end{tabular}

\section{Introduction}

Hemodiafiltration (HDF) can efficiently remove uremic toxins, from low-molecular-weight to large-molecular-weight substances, by using a combination of diffusion and convection [1-3]. More specifically, the benefits of HDF can be best utilized and good therapeutic efficacy achieved in the treatment of insomnia, pruritus, irritability, restless legs syndrome (RLS), anemia, dialysis amyloidosis (DA), etc., when removal performance of low-molecular-weight protein (LMWP) is improved [4-7].

However, if the conditions under which HDF is performed are unsuitable, the removal performance of HDF is not as high as expected, and it is difficult to differentiate from hemodialysis (HD) with a high-performance dialyzer.

$\beta_{2}$-Microglobulin $\left(\beta_{2}-\mathrm{MG}\right)$ is the substance that causes $\mathrm{DA}$, and it is widely accepted that its predialysis value is useful for evaluating the quality of dialysis therapy (quality of water purification, dialysis membrane, dialysis time, dialysis frequency, presence or absence of inflammation) [811]. In addition, $\beta_{2}-\mathrm{MG}$ is also an important biomarker for evaluating the dialysis efficiency of HD and HDF [12].

However, $\beta_{2}-\mathrm{MG}$ has a molecular weight of $11.8 \mathrm{kDa}$, which is toward the lower end of the molecular weight range of LMWPs (MW: $10-55 \mathrm{kDa}$ ), and since it can be efficiently removed by diffusion with existing high-per- 
formance dialyzers, a higher molecular weight substance should be used to evaluate removal efficiency in evaluations of the performance of HDF, in which diffusion and convection are performed simultaneously.

In this paper, we state based on our own cases what kind of marker should be used and how conditions for HDF should be set up in order to make the best use of the distinctive features and benefits of HDF.

\section{What Is a Suitable Biomarker for Evaluation of Clinical Outcomes of HDF?}

On-line HDF became formally covered by the Japanese National Health Insurance system (JNHAS) in 2010. However, four conditions were stipulated for performing it: (1) use of approved dedicated HDF equipment, (2) use of an approved hemodiafilter, (3) guarantee of dialysis water purification by each institution, and (4) DA and dialysis difficulty as indications.

We changed the dialysis conditions at our own institution to conform to the conditions stipulated for coverage by JNHAS in 17 cases that had become stable on HDF with a super high-flux dialyzer, and the result was that by one month after changing the dialysis conditions, the symptoms in 13 of the 17 cases had become worse. In 6 of these 13 cases, the dialysis method had been changed to HD with a super high-flux dialyzer, and in the other 7 cases it had been changed to HDF with a hemodiafilter that had been approved.

We then changed the dialysis conditions again in the 13 cases in which the symptoms had become worse. More specifically, we attempted to improve removal performance of dialysis by performing HDF with the super high-flux dialyzer that had been used before or performed HD with a higher performance super high-flux dialyzer, etc. The result was that one month later ADL had improved in 11 of the 13 cases, and their QOL had returned to its previous level. An improvement in QOL was also noted in the other 2 cases.

$\alpha_{1}$-Microglobulin $\left(\alpha_{1}\right.$-MG) removal rates in the 13 cases whose symptoms changed from 'stable' to 'worse' and then to 'improved' changed significantly almost exactly in tandem with the changes in symptoms from $35.5 \pm 7.7$ to $23.2 \pm 4.9 \%$ and then to $32.3 \pm 5.6 \%(\mathrm{n}=13$, all $\mathrm{p}<0.01)$. However, the corresponding changes in Kt/V from 1.59 to 1.65 and then to 1.56 and in the $\beta_{2}-\mathrm{MG}$ removal rate from 78.2 to $75.2 \%$ and then to $77.3 \%$ only fluctuated within narrow ranges. These changes show that the symptom worsening occurred because the $\alpha_{1}$-MG removal rate

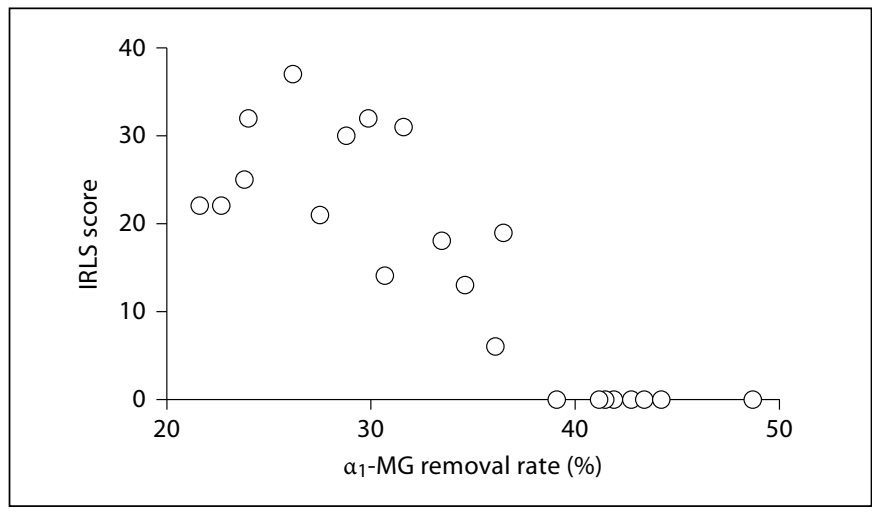

Fig. 1. Relationship between IRLS score and $\alpha_{1}-\mathrm{MG}$ removal rate. The $\alpha_{1}$-MG removal rate and IRLS score during the course of treatment of 7 cases of RLS are shown. Although the symptoms were alleviated up to $\alpha_{1}$-MG removal rates of $35 \%$, RLS was not cured, and an $\alpha_{1}-M G$ removal rate of $38 \%$ or more was needed to cure RLS.

had decreased, i.e. they occurred because of insufficient removal of uremic toxins having a molecular weight of 30 $\mathrm{kDa}$ or more, and the improvement in symptoms occurred because the removal of uremic toxins having a molecular weight of $30 \mathrm{kDa}$ or more had increased. They also showed that it is impossible to infer associations between changes in symptoms and LMWPs by assessing only $\mathrm{Kt} / \mathrm{V}$ and $\beta_{2}$-MG removal rates.

The symptoms that occurred were either the development or aggravation of bone and/or joint pain (10/13 cases), reduced activity (7/13 cases), pruritus (4/13 cases), RLS ( $3 / 13$ cases), irritability ( $2 / 13$ cases), etc. Dialysis vintage in these 13 cases was $21.0 \pm 10.1$ years, and dialysis vintage in the group that developed or experienced aggravation of bone and/or joint pain was $24.3 \pm 9.0$ years (group without these changes: $8.4 \pm 4.1$ years). When the dialysis vintages and the symptoms that developed were reviewed together, these episodes showed that continuing $\mathrm{HDF}$ at an $\alpha_{1}$-MG removal rate of $35 \%$ is advisable to prevent the onset of DA or mitigate these symptoms.

RLS symptoms have been classified into four stages by International Restless Legs Syndrome score (IRLS score): 1-10, mild; $11-20$, moderate; $21-30$, severe; $31-40$, very severe [13]. Even a review of the IRLS score and $\alpha_{1}-\mathrm{MG}$ removal rate together in the 7 cases in which RLS developed as a complication revealed that while the symptoms were alleviated up to an $\alpha_{1}-\mathrm{MG}$ removal rate of $35 \%$, the patients' RLS was not cured, and that an $\alpha_{1}$-MG removal rate of $38 \%$ or more was necessary in order to cure their RLS (fig. 1). This shows that it is impossible to hope for a cure of RLS even by increasing removal of uremic toxins 


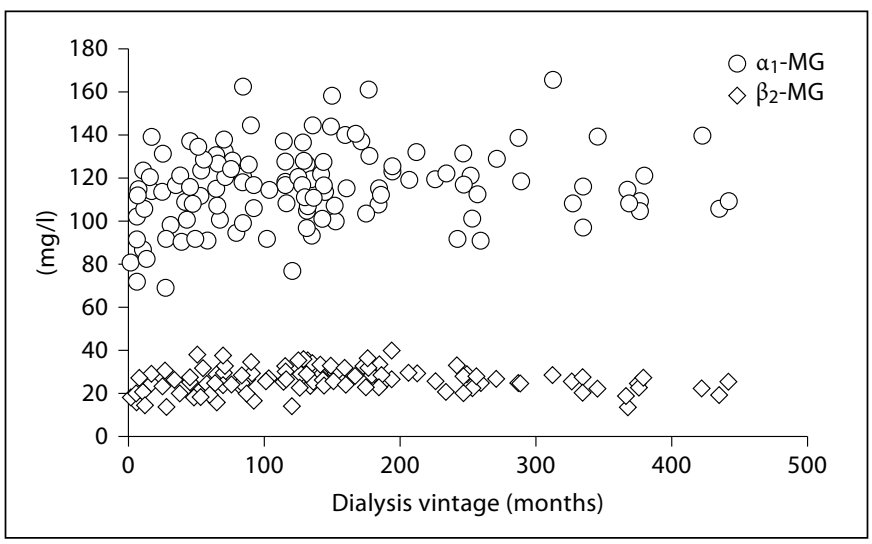

Fig. 2. Relationship between predialysis $\alpha_{1}-M G$ and $\beta_{2}-M G$ values and dialysis vintage. There were no correlations between the predialysis values of $\alpha_{1}-\mathrm{MG}$ or $\beta_{2}-\mathrm{MG}$ and dialysis vintage. Their mean values were: $\alpha_{1}-\mathrm{MG} 117.0 \pm 19.9 \mathrm{mg} / \mathrm{l}$ and $\beta_{2}$-MG $26.5 \pm 5.3$ $\mathrm{mg} / \mathrm{l}(\mathrm{n}=126$, tested August 2012).

from a molecular weight of $10-20 \mathrm{kDa}$, and that aggressively removing uremic toxins having molecular weights of $30 \mathrm{kDa}$ or more leads to a cure of RLS [14].

These assessments showed that $\alpha_{1}$-MG should be used to correctly evaluate the distinctive features and benefits of HDF.

\section{What Is $a_{1}$-MG?}

$a_{1}-\mathrm{MG}$ has a molecular weight of $33 \mathrm{kDa}$ and a Stokes radius of $28.4 \AA$. Its predialysis values are not correlated with dialysis vintage, and no associations between predialysis values and dialysis complications have been found in any studies conducted thus far (fig. 2). The predialysis $\alpha_{1}-\mathrm{MG}$ values of dialysis patients in our institution were $117.0 \pm 19.9 \mathrm{mg} / \mathrm{l}(\mathrm{n}=126)$, and the mean value of healthy subjects was $12.5 \pm 2.3 \mathrm{mg} / \mathrm{l}(\mathrm{n}=31)$.

$\beta_{2}-\mathrm{MG}$ is known to be the substance that causes DA, and many studies have been conducted regarding its etiology and $\beta_{2}$-MG. $\beta_{2}$-MG has a molecular weight of 11.8 $\mathrm{kDa}$ and a Stokes radius of $16 \AA$. The $\beta_{2}$-MG predialysis values of dialysis patients in our institution were $26.5 \pm$ $5.3 \mathrm{mg} / \mathrm{l}(\mathrm{n}=126)$, and the mean value of healthy subjects was $1.4 \pm 0.3 \mathrm{mg} / \mathrm{l}(\mathrm{n}=31)$.

The changes in $\alpha_{1}-M G$ and $\beta_{2}-M G$ values between $A u-$ gust 2011 and August 2012 in all of the cases as a whole $(\mathrm{n}=126)$ were: $\alpha_{1}-\mathrm{MG}, 119.8 \rightarrow 117.0 \mathrm{mg} / \mathrm{l}$, and $\beta_{2}-\mathrm{MG}$, $27.4 \rightarrow 26.5 \mathrm{mg} / \mathrm{l}$, and thus there was hardly any change in either of them. In an assessment of the HDF group (n $=11)$ alone, the changes were: $\alpha_{1}-\mathrm{MG}, 119.1 \rightarrow 120.3$ $\mathrm{mg} / \mathrm{l}$, and $\beta_{2}$-MG, $24.0 \rightarrow 22.9 \mathrm{mg} / \mathrm{l}$, and a tendency for the $\beta_{2}$-MG values to decrease was observed, but the difference was not significant.

Many studies have been conducted in this field since the Gejyo study in which $\beta_{2}$-MG was identified as the precursor protein of DA, but no correlations have been reported between predialysis $\beta_{2}$-MG values and the onset of DA or the severity of the symptoms $[8,9,15-17]$. Nor have there been any reports of studies that investigated the relationship between $\alpha_{1}$-MG and dialysis complications. Based on our study as well, at present predialysis $a_{1}-M G$ values have not been found to indicate the severity of the pathology or the appropriateness of the dialysis conditions, etc., but further study is needed.

Uremic toxins whose molecular weights are greater than that of $\beta_{2}$-MG may be involved in the development of clinical manifestations such as insomnia, pruritus, irritability, RLS, anemia, and osteoarticular pain. For that reason, it has been said that it will be necessary to remove a wider range of LMWPs than $\beta_{2}-M G$ and to remove protein-bound toxins in order to treat these symptoms, and the same appeared to be true in the present study of our own cases.

We wish to emphasize that the reason for removing $\alpha_{1}-M G$ is not because $\alpha_{1}$-MG itself is toxic, but because $\alpha_{1}$-MG has a molecular weight of $33 \mathrm{kDa}$ and should be used as a biomarker for evaluation of clinical outcomes of HDF. We also concluded that an increase in therapeutic efficacy, an increase in patient QOL, and a higher survival rate can be expected when the distinctive features and advantages of HDF are best utilized by setting the HDF performance conditions with an $\alpha_{1}-\mathrm{MG}$ rate of $35 \%$ as the goal.

When HDF is performed under these conditions, a $\beta_{2^{-}}$ MG removal rate of $80 \%$ can be easily achieved. On the other hand, even if the replacement fluid volume is increased, a $\beta_{2}-\mathrm{MG}$ removal rate of $80 \%$ and $\alpha_{1}$-MG removal rate of $15 \%$ are likely to be achieved by HDF with a small-pore size dialyzer or hemodiafilter.

\section{Difference in Removal Characteristic between $\beta_{2^{-}}$ MG and $a_{1}-$ MG}

We used two high-flux dialyzer models (FX, Fresenius Medical Care; FDX, Nikkiso Co., Ltd.) and one superhigh dialyzer model (FDY, Nikkiso) having a dialysis area of $1.8 \mathrm{~m}^{2}$ and assessed the relationship between $\beta_{2}$-MG and $\alpha_{1}-\mathrm{MG}$ removal rates and the amount of albumin loss when $\mathrm{HD}$, predilution on-line $\mathrm{HDF}$, and postdilution on- 
Fig. 3. Relationship between removal rate of $\beta_{2}$-MG and $\alpha_{1}$-MG and amount of albumin loss. We investigated the relationship between $\beta_{2}$-MG and $\alpha_{1}$-MG removal rate by HD, predilution on-line HDF, and postdilution on-line HDF, with two high-flux dialyzer models (FX and FDX) and one super-high dialyzer model (FDY), and the amount of albumin leakage in 6 cases. $Q_{B}$ $300 \mathrm{ml} / \mathrm{min}, \mathrm{Q}_{\mathrm{D}}$ total $500 \mathrm{ml} / \mathrm{min}, \mathrm{Q}_{\mathrm{F}} 6-21$ $\mathrm{ml} / \mathrm{min}$, pre-HDF; FX and FDX: 50 l/session, FDY: 40 1/session, post-HDF; FX and FDX: 15 l/session, FDY: 8 l/session.
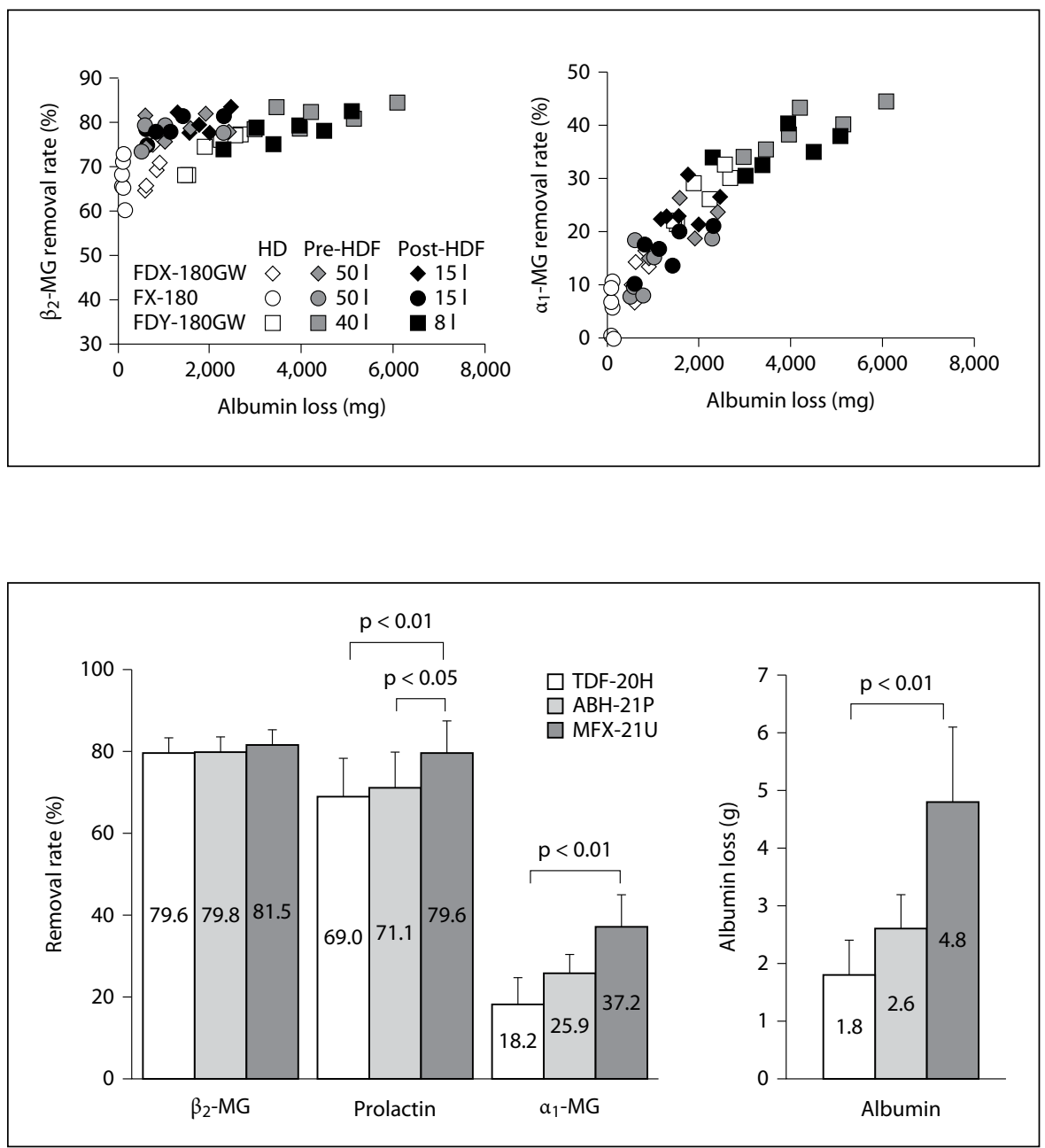

Fig. 4. Comparison of removal rates of three hemodiafilters. 50-liter predilution on-line $\mathrm{HDF}$ ( $4 \mathrm{~h}$ ) was performed at $\mathrm{Q}_{\mathrm{B}} 250$ $\mathrm{ml} / \mathrm{min}\left(\mathrm{Q}_{\mathrm{D}}\right.$ total $\left.500 \mathrm{ml} / \mathrm{min}\right)$ with TDF$20 \mathrm{H}, \mathrm{ABH}-21 \mathrm{P}$, and MXF-21U hemodiafilters, and LMWP ( $\beta_{2}-\mathrm{MG}$, prolactin, $\alpha_{1}$ $\mathrm{MG}$ ) removal rate and the amount of albumin loss were assessed $(n=7$, mean $\pm S D)$.

\section{Evaluation of Hemodiafilter Performance}

We performed 50-liter predilution online HDF (for $4 \mathrm{~h}$ ) at $\mathrm{Q}_{\mathrm{B}} 250 \mathrm{ml} / \mathrm{min}\left(\mathrm{Q}_{\mathrm{D}}\right.$ total $500 \mathrm{ml} / \mathrm{min}$ ) with TDF$20 \mathrm{H}$ (Toray Medical Co., Ltd), ABH-21P (Asahi Kasei Medical Co., Ltd), and MFX-21U (Nipro Co.), and assessed removal performance (fig. 4). These three products can be described as high-performance versions of hemodiafilters that are currently on the market in Japan.

Under these assessment conditions, all three models yielded a good $\beta_{2}-\mathrm{MG}$ removal rate of $80 \%$ [amount removed (mg): TDF, 186; ABH, 169; MFX, 190], but there were large differences in their $a_{1}$-MG removal rates: TDF, 18.2\% (amount removed: $93 \mathrm{mg}$ ), $\mathrm{ABH}, 25.9 \%$ (amount removed: $126 \mathrm{mg}$ ), and MFX, 37.5\% (amount removed: $179 \mathrm{mg}$ ), respectively. Thus, differences between the performance of the hemodiafilters became in- 
creasingly marked as molecular weight increased from the $11.8 \mathrm{kDa}$ for $\beta_{2}-\mathrm{MG}$, to $23 \mathrm{kDa}$ for prolactin, and to $33 \mathrm{kDa}$ for $\alpha_{1}$-MG. If the removal performance of the hemodiafilters had been evaluated on the basis of $\beta_{2}-\mathrm{MG}$ alone, the results for all three hemodiafilter models would have been the same. In other words, to make the best use of the distinctive features and benefits of HDF, it is important to use $\alpha_{1}-\mathrm{MG}$ as the biomarker to evaluate the removal performance of HDF, and to choose a hemodiafilter that provides an $\alpha_{1}$-MG removal rate of $35 \%$. An improvement in clinical manifestations can be expected by doing so, and it increases patients' QOL and, in turn, their survival rate.

\section{Conclusion}

The removal performance of HDF should be assessed by using $\alpha_{1}-\mathrm{MG}$ as a biomarker. Further, the distinctive features and benefits of HDF are best utilized by selecting a suitable hemodiafilter and setting an $\alpha_{1}-\mathrm{MG}$ removal rate of $35 \%$ as the target value.

\section{Disclosure Statement}

I have no relationship with the industry or financial associations that might pose a conflict of interest in connection with the submitted article.

\section{References}

1 Canaud B: The early years of on-line HDF: how did it all start? How did we get here? in Krick G, Ronco C (eds): On-Line Hemodiafiltration: The Journey and the Vision. Contrib Nephrol. Basel, Karger, 2011, vol 175, pp 93 109.

2 Tattersall J: Clearance of beta-2-microglobulin and middle molecules in haemodiafiltration; in Ronco C, Canaud B, Aljama P (eds): Hemodiafiltration. Contrib Nephrol. Basel, Karger, 2007, vol 158, pp 201-209.

3 Canaud B, Chenine L, Renaud S, et al: Optimal therapeutic conditions for online hemodiafiltration; in Kawanishi H, Yamashita AC (eds): Hemodiafiltration - A New Era. Contrib Nephrol. Basel, Karger, 2011, vol 168, pp 28-38.

4 Pedrini LA, De Cristofaro V, Comelli M, et al: Long-term effects of high-efficiency on-line haemodiafiltration on uraemic toxicity. A multicentre prospective randomized study. Nephrol Dial Transplant 2011;26:2617-2624.

5 Ronco C, Cruz D: Hemodiafiltration history, technology, and clinical results. Adv Chronic Kidney Dis 2007;14:231-243.

-6 Nakai S, Iseki K, Tabei K, et al: Outcomes of hemodiafiltration based on Japanese dialysis patient registry. Am J Kidney Dis 2001; 38:S212-S216.
7 Locatelli F, Altieri P, Andrulli S, et al: Predictors of haemoglobin levels and resistance to erythropoiesis-stimulating agents in patients treated with low-flux haemodialysis, haemofiltration and haemodiafiltration: results of a multicentre randomized and controlled trial. Nephrol Dial Transplant 2012;27:3594-3600.

8 Gejyo F, Yamada T, Odani S, et al: A new form of amyloid protein associated with chronic hemodialysis was identified as beta2-microglobulin. Biochem Biophys Commun 1985; 129:1-9.

9 Geijo F, Narita I: current clinical and pathogenetic understanding of beta2-m amyloidosis in long term hemodialysis patients. Nephrology (Carlton) 2003;8(suppl):S45S49.

10 Okuno S, Ishimura E, Kohno K, et al: Serum beta2-microgobulin level is a significant predictor of mortality in maintenance haemodialysis patients. Nephrol Dial Transplant 2009; 24:571-577.

11 Furuya R, Kumagai H, Takahasi M, et al: Ultrapure dialysis reduces level of beta2-microglobulin and pentosidine hemodialysis patients. Blood Purif 2005;23:311-316.

12 Ahrenholz PG, Winkler RE, Michelsen A, et al: Dialysis membrane-dependent removal of middle molecules during hemodiafiltration: the beta2-microglobulin/albumin relationship. Clin Nephrol 2004;62:21-28.

13 Walters AS, LeBrocq C, Dhar A, Hening W, Rosen R, Allen RP, Trenkwalder C: International Restless Legs Syndrome Study Group: Validation of the International Restless Legs Syndrome Study Group rating scale for restless legs syndrome. Sleep Med 2003;4:121-132.
14 Shinzato T, Maeda K: Push/pull hemodiafiltration; in Ronco C, Canaud B, Aljama P (eds): Hemodiafiltration. Contrib Nephrol. Basel, Karger, 2007, vol 158, pp 169-176.

15 Kazama JJ, Maruyama H, Gejyo F: Reduction of circulating beta2-microglobulin level for the treatment of dialysis-related amyloidosis. Nephrol Dial Transplant 2001;16(suppl 4):31-35.

16 Heegaard NH: $\beta_{2}$-Microglobulin: from physiology to amyloidosis. Amyloid 2009;16:151173 .

17 Gejyo F, Homma N, Suzuki Y, et al: Serum levels of beta 2-microglobulin as a new form of amyloid protein in patients undergoing long-term hemodialysis. N Engl J Med 1986; 314:585-586.

18 Akihiro CY, Kenji S: Choice of dialyzers for HDF; in Kawanishi H, Yamashita AC (eds): Hemodiafiltration - A New Era. Contrib Nephrol. Basel, Karger, 2011, vol 168, pp $146-$ 152.

19 Tomo T, Matsuyama M, Nakata T, et al: Effect of high fiber density ratio polysulfone dialyzer on protein removal. Blood Purif 2008;26:347353

20 Tomo T, Matsuyama K, Nasu M: Effect of hemodiafiltration against radical stress in the course of blood purification. Blood Purif 2004;22(suppl 2):72-77.

21 Vanholder R, Schepers E, Pletinck A, et al: An update on protein-bound uremic retention solutes. J Ren Nutr 2012;22:90-94. 